\title{
Magnetism and Microstructure Characterization of Phase Transitions in a Steel
}

\author{
M. Güler \\ Department of Physics, Hitit University, 19030 Corum, Turkey \\ Correspondence should be addressed to M. Güler; mlkgnr@gmail.com
}

Received 30 December 2013; Accepted 25 January 2014; Published 4 March 2014

Academic Editor: Hechang Lei

Copyright (C) 2014 M. Güler. This is an open access article distributed under the Creative Commons Attribution License, which permits unrestricted use, distribution, and reproduction in any medium, provided the original work is properly cited.

\begin{abstract}
We present phase transitions in a low carbon steel according to existing phases and their magnetism. Scanning electron microscope employed research to clarify and evaluate the microstructural details. Additionally, we utilized from Mössbauer spectroscopy for magnetic characteristics of different existed phases. Scanning electron microscope examinations showed that the pure state of the steel was fully in the ferrite phase with equiaxed grains. Moreover, subsequent heat treatments on the studied steel also ensured the first austenite and then pearlite phase formation. Mössbauer spectroscopy of these phases appeared as a paramagnetic single-line absorption peak for the austenite phase and ferromagnetic six-line spectra for both ferrite and pearlite phases. From Mössbauer data, we determined that the internal magnetic fields of ferrite and pearlite phases were as 32.2 Tesla and 31.3 Tesla, respectively.
\end{abstract}

\section{Introduction}

Because of their significant usage in technology and industry, detailed examinations on the solid-state phase transformations in steel drew a remarkable attention through the last century [1-3]. Applicable findings of these previous studies make steel more able to adapt quickly changing demands on daily life. Therefore, steel is the most handy and inexpensive of all materials with more than a billion tons of yearly consumption.

Steels are mainly divided into three essential categories according to their carbon content. The first category represents low carbon steel and contains maximum $0.2 \%$ C. Second category covers the medium carbon steel with $0.2 \% \mathrm{C}-$ $0.5 \% \mathrm{C}$. The third category represents the high carbon steel and includes more than $0.5 \% \mathrm{C}$ or higher carbon content [4]. It should be emphasized here that low carbon steel accommodates the highest tonnage of all steel in a given year. Structural steel for buildings and bridges, line pipes, and automotive sheet applications; those are just a few major applications for low carbon steel. Also, the characteristics of all steel types depend on their chemical compositions, preparation history, applied heat treatment behaviors, and following quenching media. All of these facts on steel cause formation of various product phases such as pearlite, bainite, and martensite [3, 5-10]. For instance, when low carbon steel cools from the austenitic region after appropriate heat treatment temperature, different percentages of austenite phase transform into a new phase including lamellar plates of ferrite and cementite $\left(\mathrm{Fe}_{3} \mathrm{C}\right)$. On the one hand, Bain introduced this newly existing phase as "pearlite." On the other hand, according to their formation temperatures, pearlite phase occurs between $550^{\circ} \mathrm{C}$ and $720^{\circ} \mathrm{C}$ in steel, whereas austenitic region lies between $910^{\circ} \mathrm{C}$ and $1535^{\circ} \mathrm{C}$ for ferrous alloys and steel [11].

From a physical outlook, the magnetic properties of steel are ultimately linked with their own microstructure, chemical atomic composition, and alloying conditions. When compared with each other, austenite phase is nonmagnetic while ferrite, pearlite, and bainite phases are magnetic. Noteworthy to mention here, Mössbauer spectroscopy is an accurate spectroscopic technique, which clarifies the internal magnetism $\left(B_{\text {int }}\right)$ and volume fractions of distinct phases in steel and alloys [12-14].

Investigations on the parent austenite decomposition into product phases such as pearlite, bainite, and martensite play a particular key role during the ferrous alloy and steel production. So, the physical properties, such as transformation 
TABLE 1: Applied heat treatments and following quench cases.

\begin{tabular}{ll}
\hline Specimen & Applied heat treatment \\
\hline A & As in received pure state \\
B & $1100^{\circ} \mathrm{C} \rightarrow 1 \mathrm{~h} \rightarrow$ water quenching \\
C & $1100^{\circ} \mathrm{C} \rightarrow 1 \mathrm{~h} \rightarrow$ air cooling \\
\hline
\end{tabular}

kinetics, morphology, and crystallography of both ferrous alloys and steel, need extensive examinations. Interpreting of these objectives allows improving the quality and applicability of steel for many industry fields.

Literature up to date especially deals with many studies about the mechanical properties of low carbon steel. However, there is still some scarcity especially on the microstructure-magnetism relation in low carbon steel. Therefore, the focus of the current study was to examine and clarify the microstructure-magnetism relation of the different phase formations in low carbon steel after various heat treatment conditions.

\section{Experimental}

AISI (American Iron and Steel Institute) 1117 type commercial low carbon steel was examined in the present study. The chemical composition of this steel was as Fe- $0.11 \%$ Cr- $0.19 \%$ C-1.14\% Mn-0.19\% Si-0.02\% P-0.01\% Ni (wt\%). The bulk sample of the steel was in the form of the cylindrical bar with $10 \mathrm{~cm}$ in length and $1 \mathrm{~cm}$ in diameter.

To reveal the microstructural details, three slabs were cut mechanically from the bulk cylindrical sample of the steel. They then were thinned to $150 \mu \mathrm{m}$ thickness. We selected a pure slab of the steel (specimen A) to discover the microstructural details without any treatment. Afterwards, second slab (specimen B) was homogenized at $1100^{\circ} \mathrm{C}$ for $1 \mathrm{~h}$ in a quartz tube. This tube subsequently quenched into water at room temperature by cracking the quartz tube. The new third slab was homogenized at $1100^{\circ} \mathrm{C}$ for $1 \mathrm{~h}$ in a quartz tube and finally cooled in air at room temperature (specimen $\mathrm{C}$ ) to compare the quenching media influence on specimen $\mathrm{B}$. Moreover, Table 1 lists the applied heat treatments of studied specimens.

Following the applied heat treatments and quenching procedure, specimens $\mathrm{A}, \mathrm{B}$, and $\mathrm{C}$ were mechanically thinned to $50 \mu \mathrm{m}$ with abrasive $\mathrm{SiC}$ papers. After grinding, all specimens were polished with a $3 \mu$ diamond paste through a conventional procedure and these thin foil samples were finally etched in 3\% Nital for SEM observations. A JEOL JSM 5600 type electron microscope was employed to research for the microstructural examinations under $20 \mathrm{kV}$ operating voltage.

Specimens examined by SEM were used for Mössbauer spectroscopy measurements. During magnetic analysis, a Mössbauer spectrometer was performed at room temperature with a $50 \mathrm{mCi}{ }^{57} \mathrm{Co}$ radioactive source spread in $\mathrm{Rh}$. Mössbauer spectra of all measured specimens were calibrated with respect to $\alpha$-Fe and isomer shift values were given to the center of the $\alpha$-Fe.

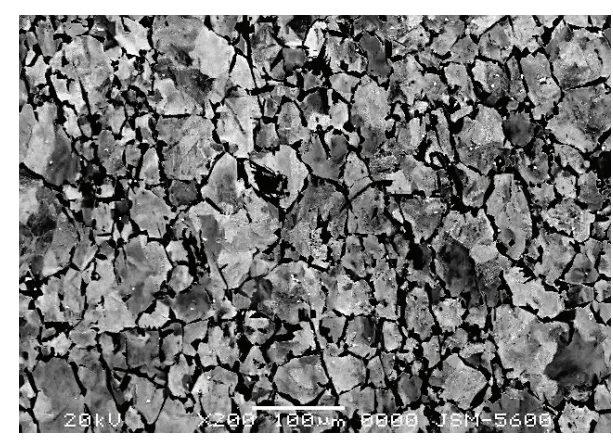

Figure 1: SEM micrograph of specimen A.

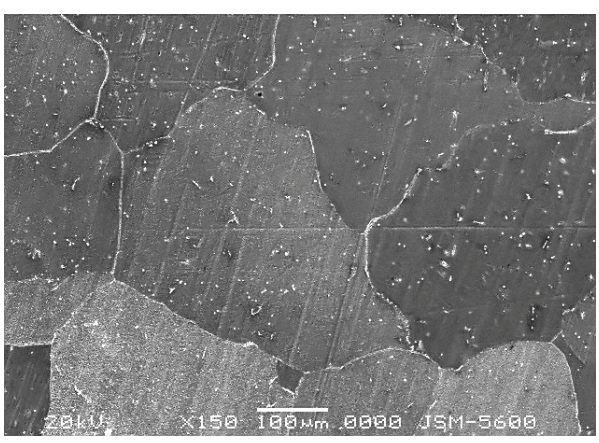

Figure 2: SEM micrograph of specimen B.

\section{Results and Discussion}

Figure 1 is a SEM micrograph taken from the specimen A. As it is obvious in Figure 1, the surface details of specimen exhibits a typical ferrite phase with the specific equiaxed grains for the pure (received) state of the steel. This phase describes the magnetic solid solution of carbon and consists of the most common microconstituent in steel. This magnetic phase appears after casting of steel, which have carbon contents lower than $0.8 \%$ [15].

Figure 2 corresponds to the SEM micrograph of B specimen. Fast cooling by water quenching caused austenite phase formation in this specimen. Further, the microstructure in Figure 2 displays the austenite phase of studied steel with typical austenite grains and grain boundaries. As well, the austenite phase forms the nonmagnetic carbon solid solution of iron. In addition, austenitic microstructures in steel are preferable because of their wide applications and uses in cutlery, hospital, and food service equipment and in tableware.

Figure 3 stands for the SEM micrograph of specimen C. Slow cooling in air at room temperature caused to coarse pearlite phase formation in $\mathrm{C}$ specimen with a lamellar morphology. Pearlite phase in steel forms with two prominent morphologies, namely, as coarse pearlite and fine pearlite. At low temperatures, nucleation step of phase transformation rapidly occurs and depresses the grain growth. Decreasing in the grain growth leads to fine-grained microstructure as fine pearlite. On the other hand, at higher temperatures, diffusion of the alloying ingredients allows the larger grain growth and leads to form coarse-grained microstructure as coarse 
TABLE 2: Determined Mössbauer parameters of specimens A, B, and C.

\begin{tabular}{lcccc}
\hline Specimen & Observed phase & Volume fraction $(\%)$ & Isomer shift $(\mathrm{mm} / \mathrm{s})$ & 0.22 \\
\hline A & Ferrite & 100 & $B_{\text {int }}($ Tesla $)$ \\
B & Austenite & 100 & 0.19 & 32.2 \\
C & Austenite + Pearlite & $12+88$ & 0.18 & - \\
\hline
\end{tabular}

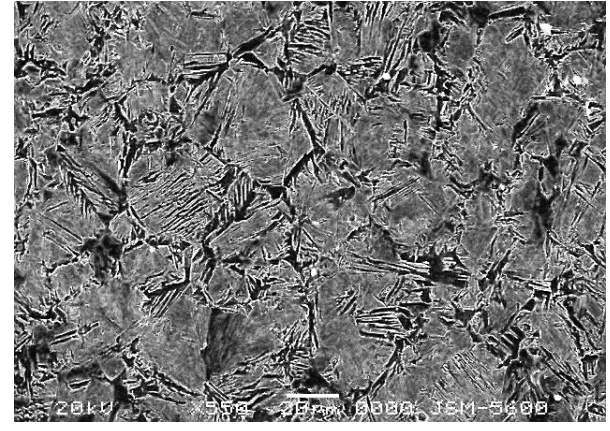

FIGURE 3: SEM micrograph of specimen C.

pearlite [16-18]. In this research, specimen $C$ of examined low carbon steel shows a typical coarse pearlite phase as in Figure 3.

From a magnetic perspective, despite the paramagnetic ordering of the parent austenite phase, product phases such as bainite, pearlite, and martensite can exhibit ferromagnetic ordering [19]. In Mössbauer spectroscopy, a single-line accompanies the paramagnetic austenite phase, whereas the product ferromagnetic phases appear with typical sextet in the spectra [8]. Figures 4, 5, and 6 show the Mössbauer spectra with the count rates versus relative velocity plots of specimens A, B, and C, respectively. Detected ferrite phase in A specimen appears with a ferromagnetic sextet in the Mössbauer spectrum as in Figure 4. Also, Figure 5 shows a paramagnetic austenite phase singlet for specimen B. Conversely, the peaks in Figure 6 indicate both paramagnetic singlet for retained austenite phase and a ferromagnetic sextet belonging to pearlite phase in specimen C. In addition, Table 2 shows some important Mössbauer data collected from all studied specimens. The volume \% transformations, internal magnetic field values, and isomer shifts of each specimen can be easily seen in Table 2 .

\section{Conclusions}

From the determined results of present experiments, we deduced and outlined the following findings.

(i) Present low carbon steel showed a ferritic microstructure (Figure 1) as in the received pure state. Further, different quenching media at constant homogenization temperature caused various phases in the studied steel. Rapid water quenching of the studied steel caused the austenite phase formation in specimen B (Figure 2), whereas slow air-cooling at room temperature caused coarse pearlite phase (Figure 3 ) formation in the specimen $\mathrm{C}$.

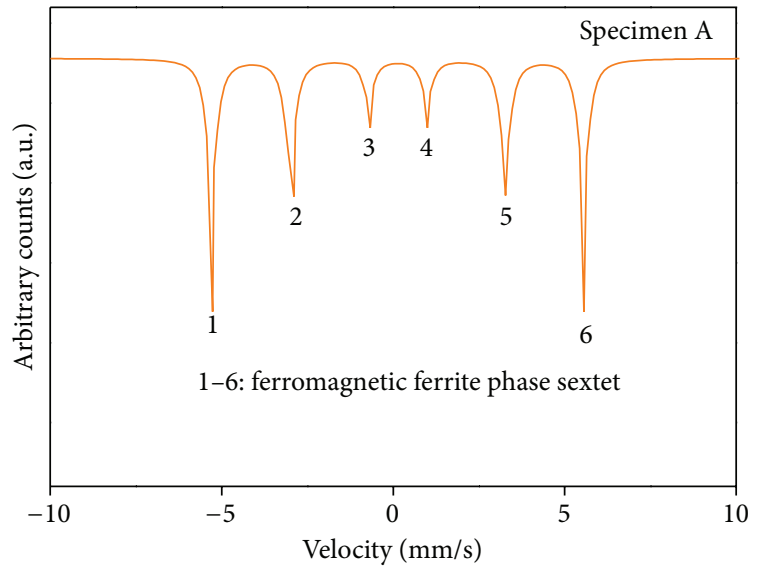

Figure 4: Mössbauer spectrum of specimen A.

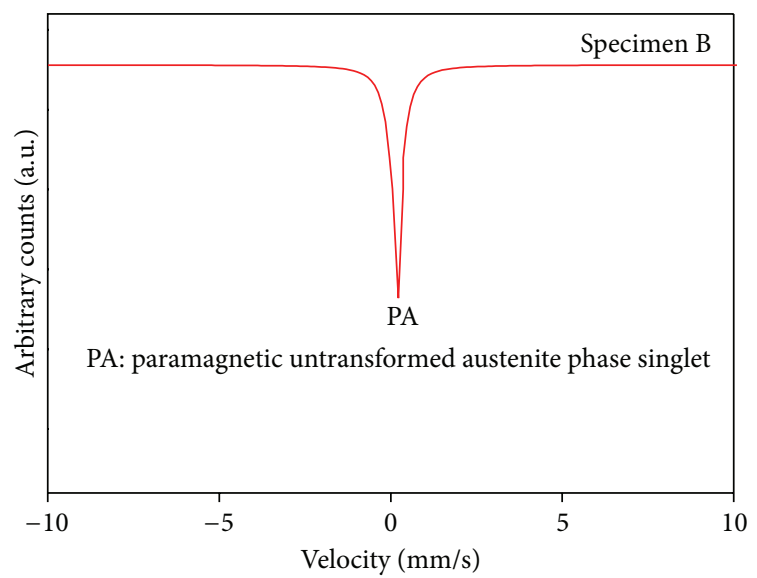

Figure 5: Mössbauer spectrum of specimen B.

(ii) Depending mainly on the steel composition and applied prior heat treatment, pearlite phase displays two common morphologies in steel as fine pearlite and coarse pearlite. We observed the coarse pearlite formation (Figure 3) in the studied steel for the present composition and heat treatment.

(iii) Determined magnetism of ferrite (Figure 4) and pearlite phases (Figure 6) explain the internal magnetic field of ferrite phase is 32.2 Tesla, and it is higher than the magnetism of pearlite phase, which has the value of 31.3 Tesla. 


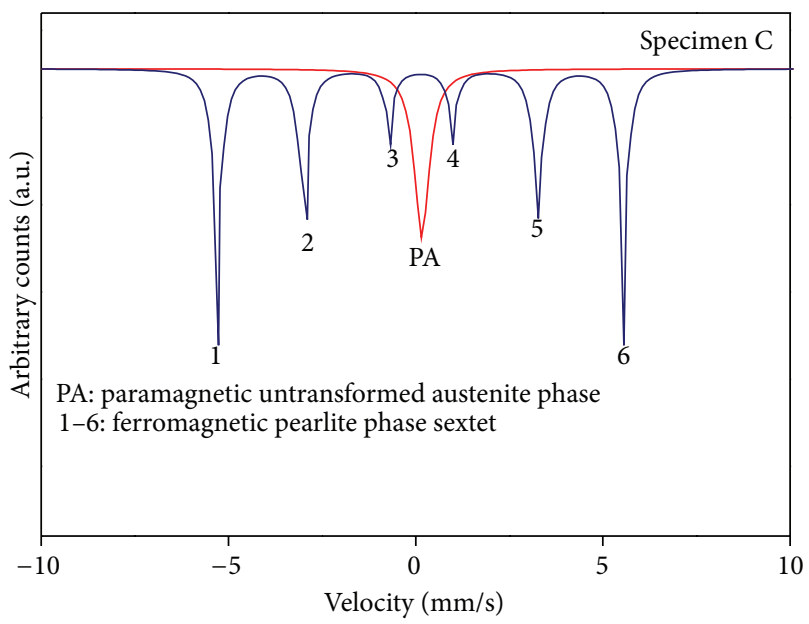

Figure 6: Mössbauer spectra of specimen C.

\section{Conflict of Interests}

The author declares that there is no conflict of interests regarding the publication of this paper.

\section{References}

[1] E. C. Bain and H. W. Paxton, Alloying Elements in Steel, American Society for Metals, Metals Park, Ohio, USA, 2nd edition, 1966.

[2] H. K. D. H. Bhadeshia and R. W. K. Honeycombe, Steels, Microstructure and Properties, Elsevier, San Diego, Calif, USA, 2006.

[3] H. K. D. H. Bhadeshia, "Alternatives to the ferrite-pearlite microstructures," Materials Science Forum, vol. 284-286, pp. 39-50, 1998.

[4] W. D. Callister, Materials Science and Engineering, John Wiley \& Sons, New York, NY, USA, 6th edition, 2003.

[5] A. M. Elwazri, P. Wanjara, and S. Yue, "The effect of microstructural characteristics of pearlite on the mechanical properties of hypereutectoid steel," Materials Science and Engineering A, vol. 404, no. 1-2, pp. 91-98, 2005.

[6] E. Güler and M. Güler, "Deformation induced martensite characterization in $\mathrm{Fe}-30 \% \mathrm{Ni}-5 \% \mathrm{Cu}$ alloy," Journal of Mining and Metallurgy B, vol. 48, no. 2, pp. 259-264, 2012.

[7] E. Güler and H. Aktaş, "Mössbauer studies on an AISI 1137 type steel," Bulletin of Materials Science, vol. 29, no. 3, pp. 303-306, 2006.

[8] M. Güner, E. Güler, and H. Aktaş, "Effect of homogenization temperature on the martensitic transformation kinetics in a Fe$32 \% \mathrm{Ni}-0.4 \% \mathrm{Cr}$ alloy," Materials Characterization, vol. 59, no. 4, pp. 498-502, 2008.

[9] M. Güler, E. Güler, and N. Kahveci, "Aspects of thermal martensite in a FeNiMnCo alloy," Micron, vol. 41, no. 5, pp. 537539,2010

[10] B. Fournier, M. Sauzay, and A. Pineau, "Micromechanical model of the high temperature cyclic behavior of $9-12 \% \mathrm{Cr}$ martensitic steels," International Journal of Plasticity, vol. 27, no. 11, pp. 18031816, 2011

[11] D. C. Madeleine, Microstructure of Steels and Cast Iron, Springer, Paris, France, 2003.
[12] R. Idczak, R. Konieczny, and J. Chojcan, "An enthalpy of solution of chromium in iron studied with ${ }^{57} \mathrm{Fe}$ Mössbauer spectroscopy," Physica B, vol. 407, no. 12, pp. 2078-2081, 2012.

[13] I. Claussen, R. A. Brand, H. Hahn, and S. G. Mayr, "Relaxation scenarios in $\mathrm{Fe}-\mathrm{Pd}$ and $\mathrm{Fe}-\mathrm{Pd}-\mathrm{Cu}$ ferromagnetic shape memory splats: short range order and microstructure," Scripta Materialia, vol. 66, no. 3-4, pp. 163-166, 2012.

[14] D. M. Minic, D. M. Minic, T. Zak, P. Roupcova, and B. David, "Structural transformations of $\mathrm{Fe}_{81} \mathrm{~B}_{13} \mathrm{Si}_{4} \mathrm{C}_{2}$ amorphous alloy induced by heating," Journal of Magnetism and Magnetic Materials, vol. 323, no. 5, pp. 400-404, 2011.

[15] F. L. G. Oliveria, M. S. Andrade, and A. B. Cota, "Kinetics of austenite formation during continuous heating in a low carbon steel," Materials Characterization, vol. 58, no. 3, pp. 256-261, 2007.

[16] A. Saha, D. K. Mondal, K. Biswas, and J. Maity, "Microstructural modifications and changes in mechanical properties during cyclic heat treatment of $0.16 \%$ carbon steel," Materials Science and Engineering A, vol. 534, pp. 465-475, 2012.

[17] S. A. Sajjadi and S. M. Zebarjad, "Isothermal transformation of austenite to bainite in high carbon steels," Journal of Materials Processing Technology, vol. 189, no. 1-3, pp. 107-113, 2007.

[18] G. Thewlis, "Classification and quantification of microstructures in steels," Materials Science and Technology, vol. 20, no. 2, pp. 143-160, 2004.

[19] E. Güler, "Phase transitions in a high-chromium and mediumcarbon steel," Materials Chemistry and Physics, vol. 107, no. 2-3, pp. 183-185, 2008. 

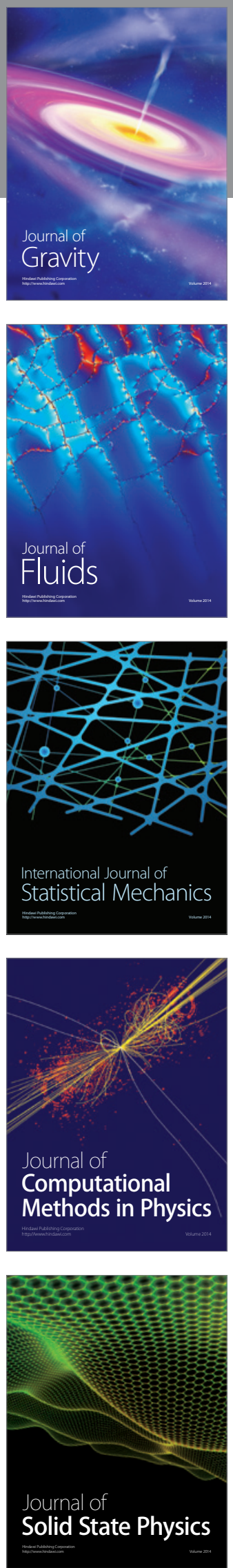

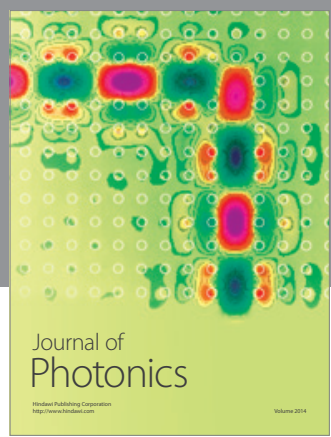

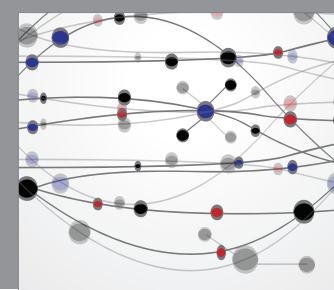

The Scientific World Journal

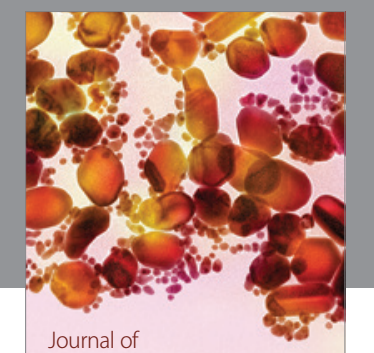

Soft Matter
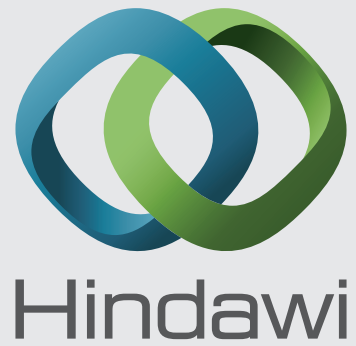

Submit your manuscripts at

http://www.hindawi.com
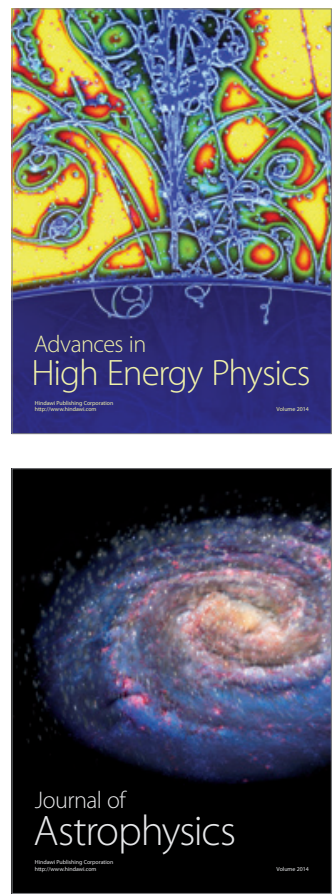
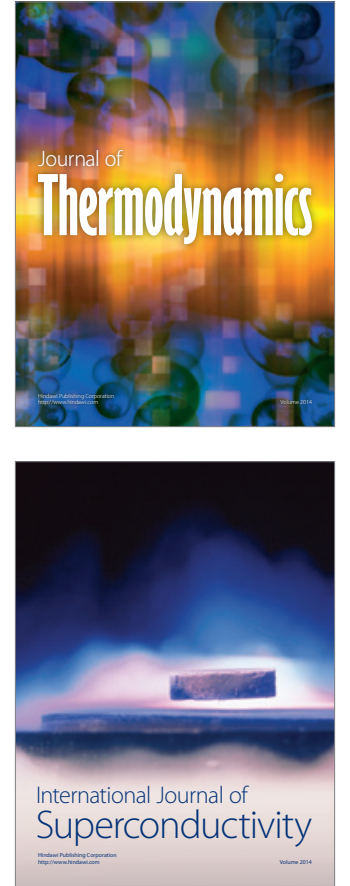
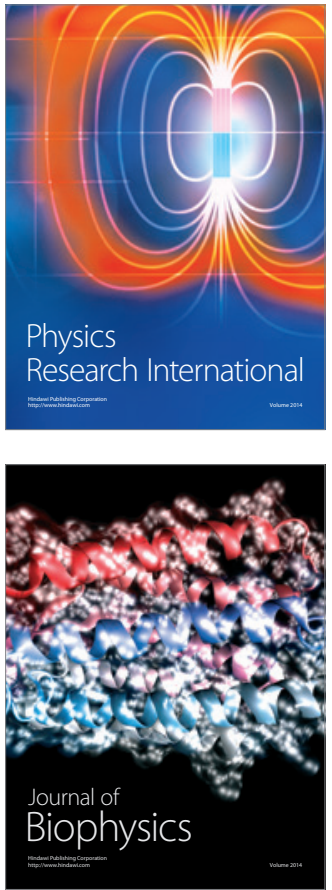
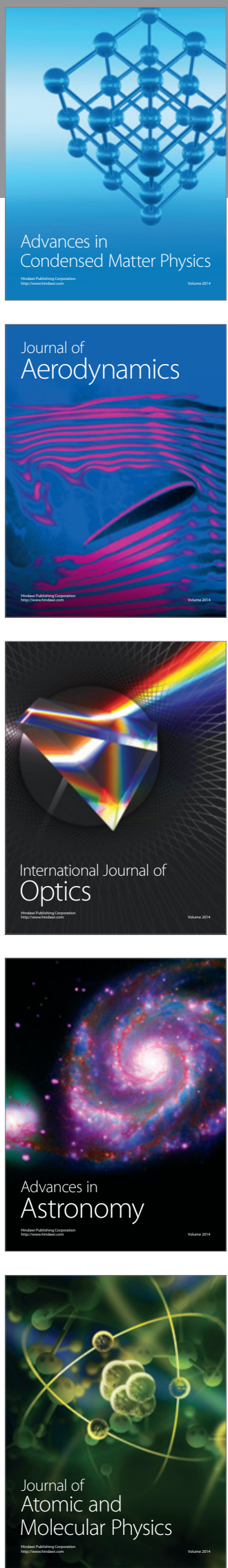